УДК 37.08

\title{
МЕТОДОЛОГИЧЕСКИЕ АСПЕКТЫ РАЗРАБОТКИ СОДЕРЖАНИЯ ВЫСШЕГО ПЕДАГОГИЧЕСКОГО ОБРАЗОВАНИЯ В УСЛОВИЯХ РЕАЛИЗАЦИИ ФГОС 3++
}

\section{Шехмирзова А.М.}

Данная статья посвящена основным методологическим аспектам разработки содержания высшего педагогического образования адекватно государственным ичелям в соответствии с соииальным заказом современного общества, методологическую основу оченки качества которого составляют федеральные государственные образовательные и профессиональные стандарты. Обзорно выявлены методологические проблемы отсутствия соответствия ичелей и содержания высшего педагогического образования. Показано, что отсутствие согласованности новых ичелей высшего педагогического образования и формулирование адекватно им содержания и структуры делают их недостижимыми, фактически несоответствуюшими желаемому. Рассматривается роль компетенциий в повымении качества подготовки педагогических кадров с учетом мировых тенденций развития системы высшего образования. Обозначены пути решения проблемы согласования целей с формулированием адекватного им содержания высшего педагогического образования.

Ключевые слова: содержание высшего педагогического образования; компетенции; качество подготовки педагогических кадров; федеральный государственный образовательный стандарт; профессиональный стандарт.

\section{METHODOLOGICAL ASPECTS \\ OF DEVELOPING THE CONTENT OF HIGHER \\ PEDAGOGICAL EDUCATION UNDER CONDITIONS OF IMPLEMENTATION OF FGOS 3 ++}

\section{Shekhmirzova A.M.}

This article is devoted to the main methodological aspects of developing the content of higher pedagogical education in accordance with state goals 
in accordance with the social order of modern society, the methodological basis of which is assessed by educational and professional standards. Methodological problems of the lack of conformity of goals and content of higher pedagogical education are surveyed. The role of competencies in improving the quality of teacher training, taking into account global trends in the development of higher education, is examined. The ways of solving the problem of matching goals with the formulation of the content of higher pedagogical education adequate to them are indicated.

Keywords: content of higher pedagogical education; competencies; the quality of teacher training; the federal state educational standard; professional standard.

В повышении качества подготовки педагогических кадров с учетом мировых тенденций развития системы высшего образования принадлежит компетенциям. По рекомендациям ЮНЕСКО и партнеров организации именно профессиональные компетенции должны выступать одним из критериев качества подготовки педагогов. М.Д. Бершадская и А.В. Серова определяют компетенции в виде комплексных характеристик готовности выпускника применять полученные знания, умения и личностные качества в стандартных и изменяющихся ситуациях профессиональной деятельности [1]. В системе российского высшего образования повышение качества массовой подготовки педагогических кадров, как отмечают исследователи, становится основой устранения возрастающих вероятностно-возможных неравенств. Поэтому, согласно определению Международной организации по стандартизации - ISO, стандарт качества представляет собой определенный набор требований, объединённых для удовлетворения потребностей обеспечения качества в данной ситуации, что сегодня отражается в государственных стандартах.

Как показывает практика, применение компетентностного подхода в условиях реализации ФГОС $3++$ столкнулось с определенными недостатками методологического характера. Во-первых, в системе российского высшего образования содержание подготовки педагогических кадров еще не структурировано адекватно поставленным 
государственным целям в соответствии с социальным заказом современного общества, выработанными профессиональным сообществом нормами - профстандартом педагога и ФГОС ВО. Именно образовательные и профессиональные стандарты составляют методологическую основу оценки качества ВО по педагогическому направлению подготовки. Они представляют собой минимальный эталон требований к квалификации выпускника вуза, что согласуется с определением стандарта качества Международной организации по стандартизации - ISO. Цели российского высшего образования еще не приведены в соответствие с инновационным содержанием подготовки будущих специалистов. Такое структурирование и придание формы будущей модели качественной массовой подготовки педагогических кадров происходит не автоматически, а через сложную научную интеллектуальную работу по формированию и структурированию инновационного содержания подготовки педагогических кадров в системе высшего образования. Как показали результаты применения метода swot-анализа, риски при формулировании качественно новых целей высшего образования (и образования в целом) проявляются в отсутствии поддержки в формулировании адекватной согласованной, гармоничной структуры и инновационного содержания высшего образования педагогических кадров. Сегодня российское общество столкнулось с проблемой, что содержание высшего образования и его структура не соответствуют декларируемым во ФГОС и профстандарте целям образования. Именно отсутствие согласованности новых целей высшего образования и формулирование адекватного им содержания и структуры сделали их недостижимыми, фактически не соответствующими желаемому. Не исследованность компетенций, начиная с универсальных, отсутствие теоретических разработок преемственного их формирования на различных этапах обучения в рамках компетентностной модели выпускника не позволяет разработать адекватное содержание образования на уровне образовательной программы [2; 3]. Тоже касается и трудовых функций профстандарта, которые должны быть согласованы с компетенциями образовательного стандарта. Выпускник 
актуализированной образовательной программы по направлению подготовки педагогическое образование сегодня должен быть готов к осуществлению профессиональной деятельности в соответствии со структурой и содержанием, обозначенных в профстандарте педагога, трудовых функций. Проводимая модернизация ОПОП предполагает овладение будущими педагогами профессиональными трудовыми действиями, указанными в соответствующем профстандарте и необходимыми для их осуществления компетенциями, представленными во ФГОС ВО. С этой целью в программах подготовки педагогических кадров должно быть задано содержание, освоение которого позволит будущему педагогу осуществить в ходе профессиональной деятельности образовательный процесс с ориентацией на развитие обучаемых с учетом их особенностей и разностороннего раскрытия личностного потенциала. По педагогическому направлению подготовки в связи с этим делается акцент на развитие психолого-педагогической компетентности будущего педагога, позволяющего выстраивать индивидуальные образовательные траектории обучаемых, создавать благоприятную образовательную среду путем освоения ряда педагогических дисциплин. Изучение же дисциплин конкретного профиля становится основой подготовки выпускников данного направления. При этом, главным (универсальным) содержанием, объединяющим в единое направление разные профили подготовки (музыка, математика, химия, география и др.) является формирование у будущих педагогов общих для этих видов деятельности компетенций и знаний, которые позволят им вне зависимости от профиля и конкретных профессиональных задач, организовывать и осуществить учебный процесс и внеурочную деятельность по направлениям развития личности обучаемых, учебно-исследовательской и проектной деятельностям. Эти компетенции по видам деятельности представлены во ФГОС ВО по педагогическому направлению подготовки (44.03.05). Во-вторых, другая методологическая проблема возникает при практическом формировании адекватного поставленным целям, содержания образования, выраженных в виде компетенций и трудовых функций. Отсутствие 
единого понимания сущности и состава компетенций, начиная с универсальных, затрудняет разработку содержания и приводит к игнорированию процедуры оценивания их сформированности на разных этапах обучения через освоения содержания образовательной программы. В российской высшей школе при доминировании предметной направленности образовательного процесса, наблюдается реализация механизма сложения результатов оценивания по отдельным знаниям и умениям. Между тем, компетенции, адекватно которым разрабатывается содержание, формируются дисциплинарными и междисциплинарными модулями образовательной программы, применяемыми образовательными технологиями системного уровня и всей образовательной средой вуза. В третьих, методологическая проблема связанна с отсутствием целостной эффективной управленческой системы реализации содержания образовательной программы. Система менеджмента качества - ISO является практическим инструментом, определяющий в вузе путь к управлению качества.

Актуализация ОПОП с учетом профстандарта позволяет согласовать цели ВО и разработать адекватное им содержание. Однако решение данной проблемы сталкивается с необходимостью разработки соответствующих индикаторов и дескрипторов достижения компетенций для всей программы педагогического направления подготовки. Это другой путь решения проблемы согласования целей с формулированием адекватного им содержания высшего педагогического образования путем договоренностей. На этом пути методологическая проблема связана с искусственным выделением некоторых компетенций из общей компетентностной модели выпускника, связанных с профессиональными задачами разных типов (во ФГОС 3++ это типы профессиональных задач). При таком подходе лучше осознается, за какую компетенцию в большей или меньшей степени несут ответственность разные элементы образовательной программы. Такой процесс более управляем, имеет промежуточную обратную связь через индикаторы и дескрипторы. Индикаторы представляют собой некоторые структурные элементы действия 
(компетенций), которые полностью описывают состав компетенций и отделяют одну из них от другой. Дескрипторы же отражают признаки проявления освоения компетенций и в отличие от индикаторов они множественны и наблюдаемы (к примеру, индикатор «анализ» не наблюдаем). Этот путь рекомендован ФУМО Министерством науки и высшего образования как более перспективный в рамках ФГОС 3++ и требует на сегодняшний день продолжения работы.

Таким образом, решение выявленных методологических проблем современной вузовской практики формирования содержания высшего педагогического образования в соответствии с целями, возможно только системно, в целом, совместными усилиями профессорско-преподавательского коллектива вуза.

\section{Сиисок литературы}

1. Бершадская М.Д. Универсальные компетенции: индикаторы, опыт разработки и оценивания [Электронный ресурс] / М.Д. Бершадская, А.В. Серова. Факультет социальных наук НИУ «Высшая школа экономики». URL: https://knastu.ru/media/files/page_files/teachers/ Bershadskaya_UK_-_indikatory_opyt_razrabot..tsenivaniya_Seminar_ AKUR_05.2018.pdf

2. Шехмирзова А.М., Грибина Л.В. Организация практики бакалавров в вузе с позиций компетентностного подхода // В мире научных открытий. № 7.7 (67), 2015. С. 2747-2759.

3. Шехмирзова А.М., Пшизова А.Р. Компетентностная модель выпускника вуза в контексте модернизации российской системы высшего образования // Paradigmata poznání. №4, 2015. С. 154-160.

\section{References}

1. Bershadskaya M.D., Serova A.V. Universal'nye kompetentsii: indikatory, opyt razra-botki i otsenivaniya [Universal competencies: indicators, development and evaluation experience]. https://knastu.ru/media/files/ page_files/teachers/Bershadskaya_UK_-_indikatory_opyt_razrabot.. tsenivaniya_Seminar_AKUR_05.2018.pdf

2. Shekhmirzova A.M., Gribina L.V. Organizatsiya praktiki bakalavrov v 
vuze s pozitsiy kompetentnostnogo podkhoda [Organization of the practice of bachelors at the university from the standpoint of the competency-based approach]. V mire nauchnykh otkrytiy [In the world of scientific discoveries]. No. 7.7 (67), 2015. P. 2747-2759.

3. Shekhmirzova A.M., Pshizova A.R. Kompetentnostnaya model'vypusknika vuza $\mathrm{v}$ kontekste modernizatsii rossiyskoy sistemy vysshego obrazovaniya [Competency model of a university graduate in the context of modernization of the Russian system of higher education]. Paradigmata poznání. No. 4, 2015. P. 154-160.

\section{ДАННЫЕ ОБ АВТОРЕ}

Шехмирзова Анджела Мухарбиевна, кандидат педагогических наук доцент

Федеральное государственное бюджетное образовательное учреждение выстего образования «Адыгейский государственный университет»

ул. Первомайская, 208, г. Майкоп, Республика Адыгея, 385016 , Российская Федерачия andsheh@mail.ru

\section{DATA ABOUT THE AUTHOR \\ Shekhmirzova Andzhela Mukharbievna,}

Adygea State University

208, Pervomayskaya St., Maykop, Republic of Adygea, 385016, Russian Federation andsheh@mail.ru 